\title{
STUDY OF MORPHOMETRY OF SCAPHOID AND ITS VASCULAR FORAMINA
}

\author{
Muralidhar Reddy Sangam.
}

Professor and HOD, Department of Anatomy, NRI Medical College, Chinakakani, Guntur, Andhra Pradesh, India.

\section{ABSTRACT}

Background: Scaphoid fractures account to $50-80 \%$ of all carpal bone injury. Morphometry of scaphoid provides knowledge which is useful in surgical reconstruction and for estimating the length of screw for internal fixation. Knowledge of distribution of vascular foramina is helpful in evaluating the vascularity of different segments of the bone.

Materials and Methods: The study was carried out on 52 dry human scaphoid bones available in the department of Anatomy, NRI Medical College, Guntur.

Results: Various morphometric parameters - length, width - proximal, distal and width of waist, length and width of dorsal sulcus, circumference of the waist, primary and secondary heights of the tubercle and circumference of the base of the tubercle were measured. More number of vascular foramina was present of the dorsal aspect with a dorsal - volar ratio of 3.42:1.

Conclusion: The morphometric data of scaphoid is useful for orthopaedicians, hand surgeons and radiologists. KEY WORDS: Scaphoid, fracture, vascular.

Address for Correspondence: Dr Muralidhar Reddy Sangam, Professor and HOD, Department of Anatomy, NRI Medical College, Chinakakani, Guntur, PIN: 522503, Andhra Pradesh, India.

Mobile: 9440668501 E-Mail: murali_sangam@yahoo.co.in

\section{Access this Article online}

\section{Quick Response code}

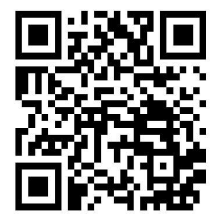

DOI: $10.16965 /$ ijar.2017.396

Web site: International Journal of Anatomy and Research ISSN 2321-4287

www.ijmhr.org/ijar.htm

Received: 05 Aug 2017

Peer Review: 07 Aug 2017

Revised: None
Accepted: 03 Oct 2017

Published (O): 01 Nov 2017

Published (P): 01 Nov 2017

\section{INTRODUCTION}

Scaphoid is the only carpal bone that links the proximal and distal carpal rows. It is the most commonly fractured bone of the wrist. Its complex shape and its orientation within the carpus make its radiological interpretation difficult [1]. Irregularity of its shape and wide area covered with articular cartilage lead to low tolerances during bone remodeling after injury. It has a retrograde blood supply that leads to relatively high rates of avascular necrosis following fracture particularly close to the proximal end. Approximately $70-80 \%$ of intraosseous vascu- larity and the entire proximal pole are supplied from the branches of radial artery entering through dorsal ridge. Remaining part of the bone in the region of distal tuberosity is supplied by volar radial artery branches [2]. Obletz et al [3] and Dubey et al [4] studied vascular foramina visible on dried scaphoid bones and described that the blood supply is predominantly distal based. Morphometric measurements may be valuable in surgical reconstruction of scaphoid which aims at restoration of normal shape. Pattern of vascular foramina helps in evaluating and explaining the risk of avascular necrosis. 


\section{MATERIALS AND METHODS}

The study was carried out on 52 (24 right and 28 left) dry human scaphoid bones obtained from the department of Anatomy, NRI Medical College, Chinakakani.

Following morphometric parameters were studied with vernier calipers of $0.02 \mathrm{~mm}$ accuracy. Circumferences were measured by placing a thread around and then measuring the length of the thread.

a) Length of scaphoid: Distance between most prominent point of proximal articular surface and the tubercle. b) Proximal width of scaphoid: Maximum width towards proximal articular surface. c) Width of waist of scaphoid: Width at the narrowest part. d) Distal width of scaphoid: Maximum width towards distal part of bone. e) Length and width of dorsal sulcus. f) Circumference of the waist. g) Primary height of the tubercle - Distance between most prominent point of the tubercle and the intersection of anterior and superior ridges of scapholunate articular surface. h) Secondary height of the tubercle - Distance between most prominent point of the tubercle and the deepest point of the waist. i) Circumference of the base of tubercle.

Number of vascular foramina was counted on the dorsal and volar surfaces with the help of hand lens.

\section{RESULTS}

Table 1: Morphometric parameters of the scaphoid (in $\mathrm{mm})$.

\begin{tabular}{|l|c|c|}
\hline & Right & Left \\
\hline a) Mean length & $24.97 \pm 2.642$ & $23.86 \pm 2.243$ \\
\hline b) Mean proximal width & $12.54 \pm 1.962$ & $12.07 \pm 2.024$ \\
\hline c) Mean width of the waist & $7.56 \pm 2.478$ & $7.27 \pm 2.136$ \\
\hline d) Mean distal width & $11.96 \pm 2.159$ & $11.6 \pm 1.864$ \\
\hline e) Mean length of dorsal sulcus & $18.62 \pm 1.766$ & $17.21 \pm 1.498$ \\
\hline f) Mean width of dorsal sulcus & $2.96 \pm 0.63$ & $2.44 \pm 0.981$ \\
\hline g) Mean circumference of the waist & $34.32 \pm 0.998$ & $32.96 \pm 1.024$ \\
\hline h) Mean primary height of the tubercle & $10.04 \pm 2.683$ & $9.56 \pm 1.974$ \\
\hline i) Mean secondary height of the tubercle & $8.26 \pm 1.986$ & $8.34 \pm 1.267$ \\
\hline$j)$ Mean circumference of the base of tubercle & $28.97 \pm 2.365$ & $28.12 \pm 2.987$ \\
\hline
\end{tabular}

Number of vascular foramina on the dorsal surface of scaphoid ranged from 1 to 10 in 6 (11.53\%) bones, 11 to 20 in 35 (67.3\%) bones and 21 to 24 in 11 (21.15\%) bones. On the volar surface vascular foramina are observed in all bones and the number ranging from $3-7 . \ln 3$ $(5.76 \%)$ bones there is no vascular foramen proximal to the mid waist, in 14 (26.92\%) bones there is one foramen and in 35 (67.3\%) bones more than one foramen is present. Distal to the mid waist vascular foramina are present in all bones - there is one foramen in 2 (3.84\%) bones and in the rest more than one is present.

\section{DISCUSSION}

Morphometry of scaphoid has a clinical significance in the management of scaphoid fractures. To assess the screw length for internal fixation preoperatively, knowledge of mean length of scaphoid is necessary [5]. In the present study, the mean length of the scaphoid is $24.97 \pm 2.642$ $\mathrm{mm}$ on the right side and $23.86 \pm 2.243 \mathrm{~mm}$ on the left side. In a study in North-Eastern population, Purushothama [6] reported the mean length of scaphoid as $22.33 \mathrm{~mm}$ and $22.65 \mathrm{~mm}$ on the right and left sides. Kigera reported the mean scaphoid length as $30.3 \pm 2.9 \mathrm{~mm}$ and stated that longer lengths of scaphoid in Kenyan and American population could be attributed to a more prominent scaphoid tubercle. Prominence of scaphoid tuberosity is associated with a greater angle for ligament attachment and this may alter the mechanical positioning of the scaphoid by its supporting structures leading to variant kinematics [7]. Other morphometric parameters observed in the present study are on par with the findings reported by Purusho thama [6] in North-Eastern population of India. But there is no significant statistical difference on right and left sides in the present study.

Number of vascular foramina is noted on both volar and dorsal surfaces of scaphoid. Owira et al [8] classified scaphoids into type I (no foramina), type II ( $1-2$ foramina) and type III (more than 2 foramina). There is no foramen proximal to the mid waist in $6 \%$ scaphoid bones as reported by Dubey et al [4], in 13\% scaphoids as observed by Obletz [3] and in 3\% bones in the present study. Owira [8] observed type I (no foramina) scaphoids in $54 \%$ cases. It can be stated that in such cases when there is a fracture of waist, there will be diminished blood supply to the proximal fragment leading to nonunion or avascular necrosis. In $26.92 \%$ bones there is one foramen and in $67.3 \%$ bones more 
than one foramen is observed in the present study. Similar findings were stated by Dubey et al [4] who reported the same in $17.72 \%$ and $82.28 \%$ bones respectively.

Dorsal sulcus contains numerous vascular foramina. In the present study more than one foramen is present in dorsal sulcus in $96 \%$ bones. This observation is on par with Purushothama [6] who reported in $92 \%$ bones, and Ceri [9] who observed more than 5 foramina in $88 \%$ bones.

Number of vascular foramina is more on the dorsal surface $(1-24)$ than volar surface $(3-7)$. This finding is consistent with Dubey et al [4] and Owira et al [8] who reported that dorsal to volar ratio is $4: 1$ and $4.23: 1$ respectively. In the present study it is 3.42:1.

Limitations: The study was carried out on available dry scaphoid bones in the department with unknown age and sex. The number of specimens is few to obtain statistically significant differences and compare the data for racial differences.

\section{CONCLUSION}

Study of morphometric features of scaphoid is useful during reconstruction of scaphoid and to assess the length of the screw for internal fixation for scaphoid fractures. Knowledge of vascular foramina helps in evaluating the vascularity of different segments of the bone and explaining the risk of avascular necrosis.

\section{Conflicts of Interests: None}

\section{REFERENCES}

[1]. Compson JP, Waterman JK, Heatley FW. The radiological anatomy of scaphoid: Part 2: Radiology. J Hand Surg Brit 1997;22:8-15.

[2]. Gelberman RH, Menon J. The vascularity of the scaphoid bone. J Hand Surg Am 1980;5:508-13.

[3]. Obletz BE, Halbstein BM. Non-union of fractures of the carpal navicular. J Bone Joint Surg 1938;20:4248.

[4]. Dubey PP, Navneet Kumar Chauhan, Siddiqui MS. Vascular foramina of scaphoid and its clinical implications. Biomedical Research 2011;22(2):201-4.

[5]. Heinzeimann AD, Archer G, Bindra RR. Anthropometry of human scaphoid. J Hand Surg 2007;32:10058.

[6]. Purushothama C, sarada RK, Konuri A, Tamang BK, Gupta C, Murlimanju. Morphological and morphometric features of scaphoid bone in north eastern population, India. Nepal Med Coll J 2011;13(1):2023.

[7]. Kigera JWM, Owira P, Saidi H. Scaphoid dimensions and appropriate screw sizes in a Kenyan population. East African Orthopaedic Journal 2017; 11: 3 5.

[8]. Owira P, Kigera J, Saidi H. Distribution of scaphoid nutrient foramina. The Annals of African Surgery 2016;13(2):49-51.

[9]. Ceri N, Korman E, Gunal I. The morphological and morphometric features of the scaphoid. J Hand Surg 2004;29:393-8.

How to cite this article:

Muralidhar Reddy Sangam. STUDY OF MORPHOMETRY OF SCAPHOID AND ITS VASCULAR FORAMINA. Int J Anat Res 2017;5(4.2):4563-4565. DOI: 10.16965/ijar.2017.396 